\title{
Mometasone implant for chronic rhinosinusitis
}

This article was published in the following Dove Press journal:

Medical Devices: Evidence and Research

16 August 2012

Number of times this article has been viewed

\section{Calvin CWei \\ David W Kennedy}

Department of Otorhinolaryngology, Head and Neck Surgery, University of Pennsylvania School of Medicine, Philadelphia, PA, USA
Correspondence: David W Kennedy Hospital of the University of Pennsylvania, Ravdin Building 5th Floor, 3400 Spruce Street, Philadelphia, PA 19104, USA

Tel + I 2| 5662697 I

$\mathrm{Fax}+\mathrm{I} 21566246$ I3

Email david.kennedy@uphs.upenn.edu
Abstract: The Propel mometasone-eluting stent (Intersect ENT, Palo Alto, CA) is the first Food and Drug Administration-approved device for delivering steroid medication into the ethmoid cavity following surgery. The implant is composed of a biodegradable polymer in a lattice pattern that expands in a spring-like fashion to conform to the walls of a dissected ethmoid cavity and contains a total of $370 \mu \mathrm{g}$ of mometasone furoate designed for gradual release over 30 days. The purpose of this article is to review the mode of action and the evidence supporting the efficacy of this novel technology. Three recently published clinical trials have demonstrated that the mometasone-eluting stent produced statistically significant reductions in inflammation, polyp formation, and postoperative adhesions. In addition, the implant has been found to significantly reduce the need for postoperative administration of oral steroids and to decrease the frequency of postoperative lysis of adhesions. Minimal adverse effects were reported in these trials and included infection, crusting, and granulation tissue formation. Although the placement of steroid-impregnated packing, stents, sponges, and gels has previously been used in the postoperative sinus cavities, the Propel mometasone-eluting stent introduces a new mechanism for localized and controlled delivery of topical therapy directly to the nasal mucosa for chronic rhinosinusitis.

Keywords: corticosteroid, adhesions, polyposis, inflammation, endoscopic sinus surgery, bioabsorbable, implant, steroid-releasing, intervention, nasal polyps, oral steroids

\section{Introduction to chronic rhinosinusitis}

Although the precise pathophysiology of chronic rhinosinusitis is unclear, many causes have been proposed, including environmental and genetic factors, anatomic variations, microbial colonization, superantigens, biofilms, fungal stimulation, atopic response, immunodeficiency, and disturbances in mucociliary clearance. ${ }^{1,2}$ Whatever the predisposing causes, there is general agreement that the disease process and patient symptoms are exacerbated by bacterial and fungal contamination in the sinuses. ${ }^{3}$ Endoscopic sinus surgery has proved effective not only as a method whereby the patency of the ciliated respiratory epithelium flow pathways are maintained, but as a method to facilitate topical administration of saline irrigations, antibiotics, and steroids. ${ }^{4}$

Despite its effectiveness, sinus surgery must be integrated with long-term medical therapy in rhinosinusitis patients for long term success, since it does not affect the underlying predisposing causes for the disorder. Accordingly, the use of topical and sometimes systemic corticosteroids is integral to the overall management of chronic rhinosinusitis. ${ }^{5}$ While topical steroids administered by a spray lack systemic side effects, middle meatal penetration appears to be low and their benefits can be further 
diminished by poor adherence and postoperative edema, discharge, or crusting. ${ }^{6}$ The use of oral steroids has multiple systemic risks including aseptic necrosis of the femoral head, calcium demineralization, posterior cataract formation, mood changes, and increases in blood glucose levels. ${ }^{7}$ Because systemic steroids have significant and potentially serious side effects, and existing topical methods of intranasal delivery of steroids are suboptimal, new ways to deliver corticosteroids and other medications directly to the nasal mucosa in a controlled fashion are actively being investigated. ${ }^{8}$ The Propel mometasone eluting stent (Intersect ENT, Palo Alto, CA) is the first Food and Drug Administration (FDA) approved device for localized, controlled steroid delivery into the ethmoid cavity following endoscopic sinus surgery.

\section{Obstacles in treating chronic rhinosinusitis}

The postoperative treatment regimen is considered by many surgeons to be as important to achieving long term favorable results as the surgery itself. ${ }^{4}$ Complications in the postoperative period, including scarring of the sinus ostia, the development of mucosal adhesions and middle turbinate lateralization, all may contribute to surgical failure. ${ }^{9}$ Perhaps even more important, persistent inflammation presenting as mucosal edema, polypoid mucosal change, or persistent polyps will also compromise results. ${ }^{10,11}$ Several intraoperative techniques have been utilized to prevent complications, including placement of packing, stents, sponges, and gels. ${ }^{12-15}$ However, none of these devices are FDA-approved for the administration of local medications.

\section{Review of the Propel sinus implant}

The Propel sinus implant is composed of mometasone furoate embedded in a biodegradable polymer in a lattice pattern that expands in a spring-like fashion to conform to the walls of a dissected ethmoid cavity. The mometasone implant is able to simultaneously mechanically dilate and deliver topical steroids to the postoperative sinus cavities. The stent is deployed within the middle meatus at the time of surgery or in the early postoperative period, and is designed to maintain the results of sinus surgery by decreasing postoperative inflammation, polyposis, adhesions, and middle turbinate lateralization. As a scaffold, the stent maintains medialization of the middle turbinate and prevents the development of scarring between the middle turbinate and the lateral nasal wall.

A total of $370 \mu \mathrm{g}$ of mometasone furoate, a topical corticosteroid used in a commercially available prescription intranasal spray, is embedded in the polymer matrix and gradually released in a controlled fashion over 30 days. The polymer matrix, made of polylactide-co-glycolide, has not been found to incite an inflammatory response in animal models. ${ }^{16}$ The bioabsorbable characteristics of the stent have been studied by visual estimation, and have been shown to be resorbed in a predictable fashion. An average of $15 \%$ of stent material was present by day 30 , and decreased to $0.2 \%$ after 60 days, showing successful absorption of the stent. ${ }^{17}$ Mometasone furoate is highly lipophilic and has been shown to reside in mucosal tissue for up to 60 days after stent placement. ${ }^{17}$

\section{Efficacy}

Three major studies have demonstrated the efficacy of the mometasone implant (Table 1). A randomized, double-blind multicenter pilot study by Murr et a $1{ }^{17}$ demonstrated that the steroid-releasing implant provided statistically significant reductions in postoperative inflammation, polyp formation, and the need for systemic steroids in the first 30 postoperative days. A total of 38 patients with chronic rhinosinusitis (confirmed by CT scan and a minimum Lund-MacKay stage of 6) who required primary or revision endoscopic sinus surgery were enrolled using an intrapatient control design whereby the patient was randomly assigned to either receive a steroid-eluting stent or an identically appearing noneluting control stent in their postoperative cavity. Follow-up assessments were performed at postoperative days 7, 14, 21, 30, 45, and 60. A standardized case-report form was used to grade inflammation, polypoid change, middle turbinate position and synechiae formation. Evaluations were performed on the day of the office visit by the surgeon. The key measured parameter was the difference between the ratings of the left and right ethmoid cavities. Compared to the control stent, the steroid-eluting stent produced statistically significant reductions in inflammation at days 21 to $45(P<0.0003)$, frequency of polyp formation $(P=0.0391)$, and frequency of significant adhesions $(P=0.0313)$. A reduced frequency of middle turbinate lateralization was found, but was not statistically significant. ${ }^{17}$

Forwith et $\mathrm{al}^{18}$ performed a prospective, multicenter, single-cohort clinical trial (ADVANCE). A total of 10 patients had unilateral stent placement and 40 patients had bilateral stent placement, for a total of 90 implanted sinuses. Steroideluting stents were placed post-operatively and follow up assessments at postoperative days 7, 14, 21, 30, 45, 60 days, and 6 months were performed utilizing the scale developed in the Murr et al study. ${ }^{17}$ The study demonstrated that the use of the steroid-releasing implant provided minimal mean ethmoid sinus inflammation scores and low rates of polypoid 
tissue formation, adhesion formation, and middle turbinate lateralization, which were comparable to the treatment arm of the Murr et al pilot study. There were also statistically significant improvements in patient reported outcomes after 6 months, as per results on the Rhinosinusitis Disability Index (RSDI) and Sinonasal Outcome Test-22 (SNOT-22). ${ }^{18}$

The third study (ADVANCE 2), ${ }^{19}$ a prospective, multicenter, randomized, controlled, double-blind trial, again used an intrapatient control design. It was designed to determine if the previous studies would translate into a reduced need for postoperative oral steroids and lysis of post-surgical adhesions. 105 patients with chronic rhinosinusitis were enrolled and underwent bilateral ethmoidectomy with a steroid-releasing implant placed on one side and a nonsteroid-releasing implant on the other. Follow-up visits were performed at postoperative days $14,30,60$, and 90 . When comparing control sinuses with nondrug-releasing implants, the drug-releasing implant provided a $29.0 \%$ relative reduction in postoperative interventions $(P=0.028)$ and a $52 \%(P=0.005)$ decrease in necessary lysis of adhesions. The relative reduction in frank polyposis was $44.9 \%(P=0.002) .{ }^{19}$

\section{Safety}

Three adverse events were reported in these three studies with a maximal period of follow up of 6 months. These events included one patient who complained of the sensation of sinus pressure and irritation attributed to the sinus surgery itself, but was exacerbated by crusting adherent to the stent $;^{18}$ one patient with crusting and granulation tissue formation required removal of the implant; ${ }^{19}$ and one patient experienced infection of the contralateral sinus after removal of the control stent. ${ }^{19}$ No device-related adverse events were reported in the pilot study. ${ }^{17}$

Additional theoretical drawbacks of the mometasone implant center around its systemic absorption and ocular safety. A total of $370 \mu \mathrm{g}$ of mometasone furoate is gradually released by the implant in a controlled fashion by diffusion over a 30-day period. The maximal daily dose that is released, even with the implantation of stents bilaterally, would be considerably lower than the $200 \mu \mathrm{g}$ once daily mometasone that has been shown to be safe and effective for the treatment of allergic rhinitis. ${ }^{20}$ In addition, previous studies have also supported the safety of intranasal mometasone in children. A randomized, placebo-controlled, double-blind, multicenter trial in children who used $100 \mu \mathrm{g}$ daily of mometasone furoate aqueous nasal spray for 1 year found no evidence of growth retardation and systemic effects on cosyntropin stimulation testing. ${ }^{21}$

Additionally, Murr et $\mathrm{al}^{17}$ sampled the serum of five patients who received bilateral steroid-eluting stents, the maximal amount of mometasone to be used in clinical practice. A series of blood samples were taken at baseline, then at days 7, 14,21, and 30. Plasma mometasone concentrations were below the quantification limit of liquid chromatography in all follow up time points in these patients. ${ }^{17}$ In addition, the mean cortisol concentrations at baseline and at all follow-up time points were within normal levels, indicating no evidence of adrenal suppression. ${ }^{17}$ Although harmful

Table I Published studies demonstrating efficacy of the Mometasone-eluting stent

\begin{tabular}{|c|c|c|c|c|}
\hline Study & Type of study & $\begin{array}{l}\text { Number of } \\
\text { sinuses implanted }\end{array}$ & Cohorts & Results \\
\hline $\begin{array}{l}\text { Pilot study } \\
\text { (Murr et } \mathrm{al}^{17} \text { ) }\end{array}$ & $\begin{array}{l}\text { Prospective, } \\
\text { multicenter, } \\
\text { randomized, } \\
\text { double-blind }\end{array}$ & 86 & $\begin{array}{l}\text { Mometasone-eluting } \\
\text { vs nondrug-eluting } \\
\text { stents }\end{array}$ & $\begin{array}{l}\text { Mometasone-eluting stent provided statistically } \\
\text { significant reduction in inflammation at days } 2 \text { I } \\
\text { to } 45(P<0.003) \text {, frequency of polyp formation } \\
(P=0.039 \mid) \text { and frequency of significant mucosal } \\
\text { adhesions }(P=0.03 \mid 3)\end{array}$ \\
\hline $\begin{array}{l}\text { ADVANCE } \\
\left(\text { Forwith et } \mathrm{al}^{18} \text { ) }\right.\end{array}$ & $\begin{array}{l}\text { Prospective, } \\
\text { multicenter, } \\
\text { single-cohort }\end{array}$ & 90 & $\begin{array}{l}\text { Mometasone-eluting } \\
\text { stent }\end{array}$ & $\begin{array}{l}\text { At I month, prevalence of polypoid edema was } \\
10 \% \text {, significant adhesions I.I\% (compared to } \\
5.3 \% \text { in treatment arm of pilot study) and middle } \\
\text { turbinate lateralization } 4.4 \% \text { (compared to } 5.3 \% \\
\text { in treatment arm of pilot study). Improvement } \\
\text { from baseline in patient-reported outcome } \\
\text { scores were statistically significant }(P<0.000 I)\end{array}$ \\
\hline $\begin{array}{l}\text { ADVANCE } 2 \\
\left(\text { Marple et } \mathrm{al}^{19} \text { ) }\right.\end{array}$ & $\begin{array}{l}\text { Prospective, } \\
\text { multicenter, } \\
\text { randomized, } \\
\text { double-blind }\end{array}$ & 210 & $\begin{array}{l}\text { Mometasone-eluting } \\
\text { vs nondrug-eluting } \\
\text { stents }\end{array}$ & $\begin{array}{l}\text { Mometasone-eluting stent provided a } 29 \% \\
\text { relative reduction in postoperative interventions } \\
(P=0.028) \text {, a } 52 \% \text { decrease in lysis of adhesions } \\
(P=0.005) \text { and a } 44.9 \% \text { relative reduction in } \\
\text { frank polyposis }(P=0.002)\end{array}$ \\
\hline
\end{tabular}

Abbreviations: $\mathrm{P}$, probability level. 
effects of intranasal steroids on bone metabolism have not yet been adequately studied, the development of osteoporosis would not be expected with the use of intranasal steroids at a dose and dosing frequency that does not suppress basal hypothalamic-pituitary-adrenal axis function. ${ }^{22}$

The ophthalmologic effects of the implant were investigated in the ADVANCE study. Baseline and end-of-treatment (day 30) measurements of intraocular pressure and dilated slit-lamp examination for lens opacities were performed. ${ }^{18}$ No clinically significant changes from baseline intraocular pressure or lens opacities were seen. In addition, no changes in nuclear sclerosis or posterior subcapsular cataract grade were noted. ${ }^{18}$ Further ocular safety tests were performed in the ADVANCE 2 trial. There were no clinically significant (an increase of $\geq 10 \mathrm{~mm} \mathrm{Hg}$ persisting for 2 weeks) increases in intraocular pressure through day 90 after stent placement. ${ }^{19}$

\section{Device-positioning technique}

The stent is deployed using a one-handed delivery device and is placed in the ethmoid cavity using direct endoscopic visualization. The stent is self-expanding and conforms to the shape of the ethmoid sinus, holding the middle turbinate in a medial position. ${ }^{17}$ Displacement of the middle turbinate attachment to the skull base is minimal, and only serves to hold the middle turbinate in a medial position after it has already been surgically manipulated. Although there have been no cadaver studies evaluating the extent of middle turbinate displacement, there have been no reports of skull base violation or CSF leak. Figures 1-3 show the implant being deployed into the right postoperative ethmoid cavity.

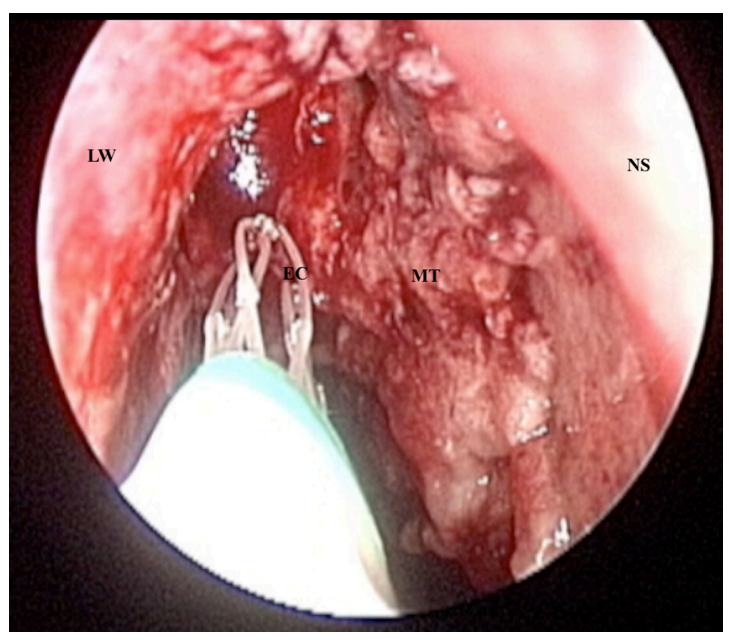

Figure I Mometasone implant being deployed into a postoperative right ethmoid cavity.

Abbreviations: LW, lateral nasal wall; EC, ethmoid cavity; MT, middle turbinate; NS, nasal septum.

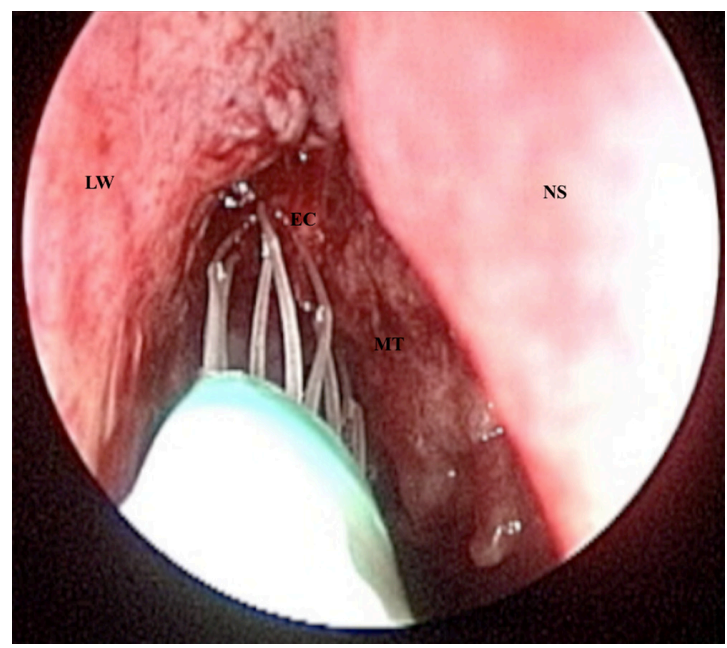

Figure 2 Mometasone implant being deployed into a postoperative right ethmoid cavity.

Abbreviations: LW, lateral nasal wall; EC, ethmoid cavity; MT, middle turbinate; NS, nasal septum.

\section{Patient preference and adherence}

No studies have yet been performed to study patient preference for this new technology when compared to previous postsurgical treatment regimens.

\section{Patient-focused perspectives, quality of life, patient satisfaction, and acceptability}

The single cohort study, ADVANCE, demonstrated significant improvements in patient-reported outcomes through 6 months. Patients who received the steroid-eluting stents were asked to complete the RSDI and the SNOT-22

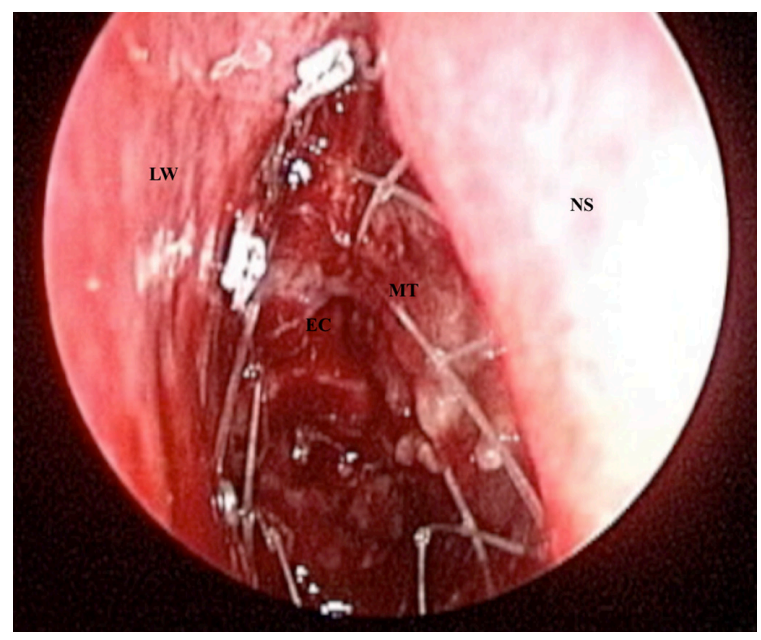

Figure 3 Mometasone implant in place holding the right middle turbinate against the nasal septum.

Abbreviations: LW, lateral nasal wall; EC, ethmoid cavity; MT, middle turbinate; NS, nasal septum. 
at baseline, 30 days, 60 days, and at 6 months after surgery. All changes from baseline in the RSDI and SNOT-22 instruments reflected statistically significant improvement $(P<0.0001){ }^{18}$

\section{Conclusions and future perspectives}

Although only three clinical trials have been performed on the mometasone implant for chronic rhinosinusitis, adverse effects that have been reported have been limited to infection and crusting requiring removal of the stent. Early data demonstrate that the mometasone implant is effective at diminishing the extent of postoperative inflammation, polyposis, mucosal adhesions, and middle turbinate lateralization after sinus surgery. By doing so, the implant maintains the results of sinus surgery and reduces the need for oral steroids. It may also diminish the extent of postoperative debridements necessary to prevent the development of mucosal adhesions and scarring. ${ }^{23}$ Development of better devices for topical steroid irrigations may also reduce the need for lysis of postoperative adhesions.

Although the mometasone-eluting stent that is currently undergoing investigation is designed for the postoperative ethmoid sinus cavity, other devices may be designed to conform to the frontal, sphenoid, and/or maxillary sinuses. In the longer term, a similar platform could also be impregnated with other medications or combination of medications to include antibiotics and other anti-inflammatory agents.

The introduction of balloon dilatation of the sinuses creates potentially interesting future options for the treatment of chronic rhinosinusitis. ${ }^{24}$ Looking forward, utilization of steroid-eluting stents in combination with balloon dilatation may provide an interesting and minimally invasive option that controls the underlying inflammation in chronic rhinosinusitis that occurs in conjunction with sinus ostial dilatation. Regardless, the steroid-eluting stent has been found in these early studies to be effective at maintaining the results of endoscopic sinus surgery both in terms of healing the postoperative cavity, reducing the need for postoperative oral steroids, and improving patient-reported outcomes. ${ }^{17-19}$

\section{Disclosures}

Calvin Wei has no disclosures to report. David Kennedy serves on the Medical Advisory Board of Intersect ENT and receives royalties from Medtronic Xomed.

\section{References}

1. Bernstein JM, Kansal R. Superantigen hypothesis for the early development of chronic hyperplastic sinusitis with massive nasal polyposis. Curr Opin Otolaryngol Head Neck Surg. 2005;13(1):39-44.

2. Kilty SJ, Desrosiers MY. The role of bacterial biofilms and the pathophysiology of chronic rhinosinusitis. Curr Allergy Asthma Rep. 2008;8(3):227-233.

3. Benninger MS, Ferguson BJ, Hadley JA, et al. Adult chronic rhinosinusitis: definitions, diagnosis, epidemiology, and pathophysiology. Otolaryngol Head Neck Surg. 2003;129(3 Suppl):S1-S32.

4. Senior BA, Kennedy DW, Tanabodee J, Kroger H, Hassab M, Lanza D. Long-term results of functional endoscopic sinus surgery. Laryngoscope. 1998;108(2):151-157.

5. Stjarne P, Olsson P, Alenius M. Use of mometasone furoate to prevent polyp relapse after endoscopic sinus surgery. Arch Otolaryngol Head Neck Surg. 2009;135(3):296-302.

6. Joe SA, Thambi R, Huang J. A systematic review of the use of intranasal steroids in the treatment of chronic rhinosinusitis. Otolaryngol Head Neck Surg. 2008;139(3):340-347.

7. Schacke H, Docke W, Asadullah K. Mechanisms involved in the side effects of glucocorticoids. Pharmacol Ther. 2002;96(1):23-43.

8. Kalish LH, Arendts G, Sacks R, Craig JC. Topical steroids in chronic rhinosinusitis without polyps: a systematic review and meta-analysis. Otolaryngol Head Neck Surg. 2009;141(6):674-683.

9. Bernstein JM, Lebowitz RA, Jacobs JB. Initial report on postoperative healing after endoscopic sinus surgery with the microdebrider. Otolaryngol Head Neck Surg. 1998;118(6):800-803.

10. Bugten V, Nordgard S, Steinsvag S. The effects of debridement after endoscopic sinus surgery. Laryngoscope. 2006;116(11):2037-2043.

11. Ramadan HH. Surgical causes of failure in endoscopic sinus surgery. Laryngoscope. 1999;109(1):27-29.

12. Cote DW, Wright ED. Triamcinolone-impregnated nasal dressing following endoscopic sinus surgery: a randomized, double-blind, placebo-controlled study. Laryngoscope. 2010;120(6):1269-1273.

13. Bednarski KA, Kuhn FA. Stents and drug-eluting stents. Otolaryngol Clin North Am. 2009;42(5):857-866.

14. Miller RS, Stewart DL, Tami TA, et al. The clinical effects of hyaluronic acid ester nasal dressing (Merogel) on intranasal wound healing after functional endoscopic sinus surgery. Otolaryngol Head Neck Surg. 2003;128(6):862-869.

15. Beule AG, Scharf C, Biebler KE, et al. Effects of topically applied dexamethasone on mucosal wound healing using a drug-releasing stent. Laryngoscope. 2008;118(11):2073-2077.

16. Li PM, Downie D, Hwang PH. Controlled steroid delivery via bioabsorbable stent: safety and performance in a rabbit model. Am J Rhinol Allergy. 2009;23(6):591-596.

17. Murr AH, Smith TL, Hwang PH, et al. Safety and efficacy of a novel bioabsorbable, steroid-eluting sinus stent. Int Forum Allergy Rhinol. 2011;1(1):23-32.

18. Forwith KD, Chandra RK, Yun PT, Miller SK, Jampel HD. ADVANCE: a multi-site trial of bioabsorbable steroid-eluting sinus implants. Laryngoscope. 2011;121(11):2473-2480.

19. Marple BF, Smith TL, Han JK, et al. ADVANCE II: a prospective, randomized study assessing safety and efficacy of bioabsorbable steroidreleasing sinus implants. Otolaryngol Head Neck Surg. 2012;146(6): 1004-1011.

20. Graft D, Aaronson D, Chervinsky P, et al. A placebo- and active-controlled randomized trial of prophylactic treatment of seasonal allergic rhinitis with mometasone furoate aqueous nasal spray. J Allergy Clin Immunol. 1996;98(4):724-731.

21. Schenkel EJ, Skoner DP, Bronsky EA, et al. Absence of growth retardation in children with perennial allergic rhinitis after one year of treatment with mometasone furoate aqueous nasal spray. Pediatrics. 2000;105(2):e22.

22. Allen DB. Systemic effects of intranasal steroids: an endocrinologist's perspective. J Allergy Clin Immunol. 2000;106(4 Suppl):S179-S190. 
23. Han JK, Marple BF, Smith TL, et al. Effect of steroid-releasing sinus implants on postoperative medical and surgical interventions: an efficacy meta-analysis. Int Forum Allergy Rhinol. May 1, 2012. [Epub ahead of print.]
24. Stewart AE, Vaughan WC. Balloon sinuplasty versus surgical management of chronic rhinosinusitis. Curr Allergy Asthma Rep. 2010; 10(3):181-187.

\section{Publish your work in this journal}

Medical Devices: Evidence and Research is an international, peerreviewed, open access journal that focuses on the evidence, technology, research, and expert opinion supporting the use and application of medical devices in the diagnosis, treatment and management of clinical conditions and physiological processes. The identification of novel devices and optimal use of existing devices which will lead to improved clinical outcomes and more effective patient management and safety is a key feature. The manuscript management system is completely online and includes a quick and fair peer-review system. Visit http://www. dovepress.com/testimonials.php to read real quotes from authors.

Submit your manuscript here: http://www.dovepress.com/medical-devices-evidence-and-research-journal 